\title{
O USO DA TECNOLOGIA NO ENSINO JURÍDICO: O MÉTODO DO ENSINO HÍBRIDO NO CURSO DE DIREITO
}

\author{
THE USE OF TECHNOLOGY IN LEGAL TEACHING: THE BLENDED LEARNING \\ METHOD IN THE LAW SCHOOL
}

\author{
Taísa llana Maia de Moura ${ }^{1}$ \\ Mônica Mota Tassigny ${ }^{2}$ \\ Thomaz Edson Veloso Silva ${ }^{3}$
}

\begin{abstract}
Resumo: O número de cursos superiores de direito no Brasil cresceu consideravelmente, o que impacta, naturalmente, na quantidade de estudantes da área, por esta razão, o presente estudo tem como objetivo identificar e debater dificuldades encontradas no ensino superior jurídico para propor um processo metodológico que possa colaborar com o melhor rendimento das aulas. A relevância de um novo planejamento na estrutura e na condução das aulas visa à melhoria dos níveis educacionais dos discentes que, por muitas vezes, saem da faculdade e não conseguem obter êxito no exame da Ordem dos Advogados do Brasil, o que dificulta o desenvolvimento da sua vida profissional. o presente artigo indica a metodologia do ensino híbrido nas Instituições de Ensino Superior (IES) de direito como proposta de atualização e melhoria para as faculdades. A proposição visa a unir dois elementos: a tecnologia e a sala de aula na direção de potencializar a capacidade e um melhor rendimento do aluno em desenvolver as matérias discutidas em sala. A metodologia utilizada, para a realização desta pesquisa, foi qualitativa e bibliográfica.
\end{abstract}

Palavras-chave: inovação; qualidade do ensino jurídico; ensino híbrido; metodologia ativa de aprendizagem; tecnologia.

Abstract: The number of law schools in Brazil has grown considerably, which has an impact on the number
of students in the area. For this reason, the present study aims to identify and discuss difficulties faced in
law schools in order to propose a methodological teaching approach that can benefit the students'
comprehension. The relevance of an updated course plan regarding the classroom structure and teacher
guidance may contribute to raise the educational levels of students who often graduate at Brazilian law
schools and cannot succeed in the Brazilian Bar Association exam, which makes it difficult to develop their
professional life. This article indicates the blended learning methodology in undergraduate law courses as a
proposal of update and enhancement for the schools. The proposal aims to unite two elements: technology
and the classroom, in the direction of boosting the ability and a better performance of the student in
developing the subjects discussed in the classroom. The methodology used to conduct this research was
qualitative and bibliographical. Keywords: innovation; legal education quality; blended learning; active methodology for learning; technology.

\footnotetext{
${ }^{1}$ Mestranda em Direito Constitucional no Programa de Pós-Graduação em Direito da Universidade de Fortaleza - PPGD/UNIFOR, CE, Brasil. E-mail: taisa@edu.unifor.br.

2 Professora Titular do Programa de Pós-Graduação em Direito da Universidade de Fortaleza - PPGD/UNIFOR, CE, Brasil. E-mail: monica.tass@gmail.com.

${ }^{3}$ Bolsista de Pós-doutorado Júnior do CNPq pela Universidade Federal do Ceará - UFC, CE, Brasil. E-mail: thomazveloso@gmail.com.
} 


\section{INTRODUÇÃO}

Falar sobre ensino híbrido implica falar em inovações metodológicas e tecnológicas na aprendizagem, tanto no que diz respeito ao papel do professor, quanto no que diz respeito ao papel do aluno dentro de uma sala de aula e na colaboração da instituição de ensino para implantar novas metodologias de ensino.

No século $X X I$, a invasão tecnológica tem emergido em todos os segmentos, em consequência disso, faz-se necessária uma readequação também no que diz respeito à educação. Em tempos de modernização, há uma cobrança para a ruptura do modelo tradicional de ensino. No atual cenário, é impossível desconsiderar inovações tecnológicas, bem como de acesso à informação. Todos os dias é possível aprender novos conteúdos na internet. É como se fossemos alunos a vida inteira. Seria, então, possível integrar essas novas tecnologias ao atual modelo de ensino universitário? Mais precisamente, no ensino superior jurídico?

Para que se obtenha a resposta desse questionamento, faz-se necessária, preliminarmente, uma análise da evolução do ensino, de uma maneira geral, até a evolução do ensino jurídico no Brasil. Abordando as metodologias de ensino feitas anteriormente para a atual, com o objetivo de estimular uma ponderação sobre o presente e o passado, com a finalidade de impulsionar a melhoria do ensino.

Conhecido como método catequético, método mais comum na educação, em que professores entram em sala, expõem o conteúdo e fazem avaliações. O professor tem o domínio da matéria e este repassa ao aluno de forma a privilegiar o ato de repetição e memorização do conteúdo. Por meio de aulas expositivas, "deposita", na cabeça do aluno, conceitos a serem cobrados; posteriormente, em avaliações, quando, então, aquele obtém o "extrato" daquilo que foi depositado.

Esse método não é de um todo descartável, não é o que se pretende comprovar com esta pesquisa. O objetivo do presente estudo é asseverar que a forma de ensino jurídico deve ser repensada devido às mudanças significativas na sociedade e os avanços tecnológicos, por isso, expõe-se a proposta de aplicação da metodologia do ensino híbrido às faculdades de direito.

A metodologia do ensino híbrido será exposta para que possa ser levada em consideração, inicialmente, em algumas matérias e a determinados professores no curso de direito. Apesar do esforço individual de alguns alunos, muitos têm dificuldades por não conseguirem distinguir a direção que devem tomar ou o que realmente querem fazer após o curso, pois muitos não possuem ainda a maturidade que um curso de nível superior necessita e acabam por adotar tecnicismos e fórmulas passadas e repassadas pelos professores como único objetivo de concluir o curso.

Além de profissionais para o mercado, o ensino superior deve promover pesquisas para aprimorar e amadurecer os alunos. As universidades, por exemplo, precisam ter 
como meta o estabelecimento do tripé pesquisa-ensino-extensão para justificar, frente à sociedade, a razão de sua existência na formação de profissionais capacitados.

Nesse sentido, a Coordenação de Aperfeiçoamento de Pessoal do Ensino Superior (CAPES), assim como o Conselho Nacional de Desenvolvimento Científico e Tecnológico (CNPq), além de órgãos estaduais de fomento à pesquisa, representam fontes de estímulos para o aluno iniciar seus estudos no campo científico, uma vez que têm sido oferecidas bolsas e premiações em dinheiro a alunos que se destacam na pesquisa científica. De outro modo, algumas universidades proporcionam, também, para a promoção de investigações científicas, encontros científicos que oportunizam a exposição e publicação de produções científicas.

Expostas as considerações supramencionadas e, reconhecendo-se que existem iniciativas importantes, busca-se identificar e debater dificuldades da atual configuração das salas de aula no ensino superior e, por meio de pesquisa bibliográfica, de abordagem qualitativa, apresentar uma nova forma metodológica de ensino a ser aplicada. Abordam-se as perspectivas para a implantação do ensino híbrido no ensino acadêmico, especificamente, no ensino jurídico.

\section{A EVOLUÇÃO DO ENSINO: DO TRIVIUM E O QUADRIVIUM AO ENSINO JURÍDICO NOS TEMPOS ATUAIS}

Afirma Émile Durkheim (1995, p. 289) que uma das mais antigas formas de organização de estudo se divide em dois ciclos: o trivium e o quadrivium, que seriam as Artes Liberais. No período da antiguidade clássica, as artes liberais eram os temas considerados essenciais para uma pessoa livre. Na idade média, foram as disciplinas essenciais para quem pretendesse o sacerdócio ou qualquer lugar na hierarquia eclesiástica.

O trivium relaciona-se com uma forma de ensinar, mas que, na verdade, proporciona o auxílio na produção de pensamentos. Composto pelas disciplinas: gramática, lógica e retórica, é um conjunto de conhecimentos que abrange desde a forma da escrita, o significado das palavras, a lógica do pensamento até ao uso da linguagem que deveria ser escolhida para comunicar e ensinar o que se compreendeu. O trivium tinha como objetivo o provimento de disciplina à mente, para encontrar expressão na linguagem, principalmente no estudo da matéria e do espírito. Já o quadrivium seria um conjunto de disciplinas relacionadas com as coisas, agregando conhecimentos associados à aritmética, geometria, música e astronomia.

Claudino Piletti e Nelson Piletti (2012, p. 30) afirmam, em seu livro, que Platão acreditava numa forma de ensino na qual não devia sequer se repassar conhecimentos aos alunos, mas sim deixá-los à vontade para se desenvolverem. O correto, em seu entendimento, deveria ser: deixar que os alunos fiquem livres para buscar conhecimento 
e, por meio da conversa ou do debate, encontrassem suas próprias respostas, não defendendo métodos autoritários de ensino.

O referido autor também aponta algumas causas para o fracasso na educação, no entendimento de Santo Agostinho, que seria: "a pouca capacidade do mestre, a repetição cansativa de conhecimentos, a reduzida inteligência do educando e a desatenção do aluno". (PILETTI; PILETTI, 2012, p.46).

No formalismo dessa cultura intelectual, as ideias reinantes continuam em vigor. Como preleciona Paulo Freire (1987, p. 33 e 34), o método expositivo ou modelo "bancário", que tem um caráter paternalista, com uma tendência a anular o poder do criador dos alunos ou, pelo menos, minimizá-lo, incentivando a continuar na ingenuidade.

Dessa forma, ao se estudar o ensino na faculdade de direito, deve ser feita uma análise acerca do desenvolvimento histórico do referido curso no Brasil, para que se possa contextualizar as mudanças, por intermédio do tempo até o cenário atual.

No período colonial no Brasil, não foram criadas universidades, aqueles que desejavam a formação em ensino superior, um pequeno número de pessoas, buscavam a Universidade de Coimbra. (SILVA; SERRA, 2017, p. 2618). Os formandos oriundos da referida universidade trouxeram para o Brasil os pensamentos e ideias iluministas que se associaram ao desejo de independência de muitos da época.

Em 1822, foi proclamada a independência do Brasil, mas o debate acerca da necessidade de criação de uma escola jurídica no Brasil já estava presente na Assembleia Constituinte de 1823. Diante de sua dissolução, por D. Pedro I, o projeto sobre o ensino jurídico brasileiro não esteve presente na Carta Constitucional de 1824. A implantação do ensino no campo do direito aconteceu em 1827, mas a instalação só ocorreu no ano seguinte, em São Paulo e em Olinda. (SILVA; SERRA, 2017, p. 2619). Fundada em 28 de março de 1828, o primeiro curso estava localizado no Convento de São Francisco, na capital paulista, e o segundo, criado em 15 de maio de 1828, em Olinda, no Mosteiro de São Bento.

As matérias que compunham a grade curricular desses cursos jurídicos estavam associadas ao Direito Natural (jus naturalismo), além delas, também estavam incluídas disciplinas que explicavam a religião do Estado, fatos e direitos sobre a monarquia e moral e bons costumes de época (BENTO; SANCHES, 2009). Com o desenvolvimento do estudo e o avanço histórico, significativas mudanças ocorreram nos cursos jurídicos brasileiros.

A primeira, em 1854, por meio do Decreto $n^{\circ} 1.386$, com a mudança de curso jurídico para Faculdades de Direito; e, a segunda, em 1879, com o surgimento das faculdades que não eram faculdades oficiais, mas possuíam autorização de ensino e deviam seguir as regras estabelecidas pelos ditames oficiais, isso ocorreu com a implementação da reforma do "ensino livre" (MOSSINI, 2010, p. 81). Já, no início do 
Século XX, em 1927, o desenvolvimento do curso gerou um número de 14 cursos de Direito, com um total de 3.200 alunos matriculados (SIQUEIRA, 2000, p. 2620).

Mesmo com o crescimento no número de cursos de direito, o ensino jurídico aparentemente fica estagnado, no viés qualitativo, em razão das matérias e conteúdos jurídicos permanecerem inalterados desde a sua criação. A primeira mais significativa reforma foi feita por Francisco Campos, em 1931, que institucionalizou a figura da universidade no Brasil (MOSSINI, 2010, p. 92).

Naquela época, surge a Ordem dos Advogados do Brasil (OAB), criada em 1930, em que foi elaborada a primeira Lei Federal 4.215/1963 (atualmente revogada), que ficou conhecida com o Estatuto da $\mathrm{OAB}$, apresentando os primeiros requisitos para 0 exercício da profissão, como as provas do exame de ordem (ao final do curso) ou a obrigatoriedade do estágio, quando ainda estudante, no último período (SILVA; SERRA, 2017, p. 2621).

Essas e outras mudanças que ocorreram posteriormente não foram suficientes para reconfigurar o ensino jurídico no país. Foi somente em 1994, devido à Portaria $n^{\circ} 1.886 / 94$ do Ministério da Educação, que houve exigências transformadoras para os estudantes do curso de direito, incluindo a exigência de nota mínima no exame de ordem, concomitantemente com outros requisitos, tais sejam: trabalho de conclusão de curso, estágio obrigatório etc (MOSSINI, 2010, p. 97-98).

Havendo, entre outras alterações, mudanças nas grades curriculares pelo Artigo $3^{\circ}$ da resolução 9/2004 do Conselho Nacional de Educação (CNE), incluindo matérias com conteúdos relacionados à antropologia, ciências políticas, economia, ética, filosofia, entre outras.

Diante do início do curso, em 1928, até os dias atuais, quase 200 anos depois, fica evidente que há uma necessidade de readequação para superar problemas apresentados por uma sociedade global e em ritmo de mudanças, pois esta exige muito mais que habilidades cognitivas. Essas mudanças devem ocorrer em ambos os aspectos, tanto no que diz respeito a reformular e atualizar os currículos nas universidades, mas também na didática/metodologia da sala de aula, de modo a preparar os estudantes para as demandas impostas pelo mundo do trabalho (CHRISTENSEN; EYRING, 2014, p. 10).

Em um fluxo de contrassenso, ao invés de encontrar uma solução para elevar os níveis do curso de direitos, nos últimos anos, houve uma proliferação de faculdades, oferecendo o referido curso no Brasil. Isso ocorreu devido à autorização do Ministério da Educação (MEC), com dados que superam mais de 1000 cursos de direito autorizados (FOREQUE, 2013, p. 1), o que gerou, por consequência, um grande número de matrículas no curso, apesar do baixo número de concluintes. Em 2016, o Censo de Educação Superior divulgou os principais resultados de sua pesquisa, especificamente o direito, tem-se, conforme Tabela 1: 
Tabela 1. Número de alunos matriculados e concluintes no curso de direito.

\begin{tabular}{l|l|l|l}
\hline Curso: Direito & $\mathbf{N}^{\circ}$ de matrículas & $\mathbf{N}^{\circ}$ de ingressantes & $\mathbf{N}^{\circ}$ de concluintes \\
\hline 2013 & 769.889 & 237.532 & 95.118 \\
2014 & 813.454 & 258.867 & 95.751 \\
2015 & 853.211 & 258.143 & 105.324 \\
2016 & 862.324 & 255.128 & 107.909 \\
\hline
\end{tabular}

Fonte: Instituto..., 2016.

O curso de direito figura-se como um dos mais procurados pelos estudantes que buscam o ensino superior; por isso, o "mercado das faculdades" tem tanto interesse na implantação do curso. Recentemente, no final de 2017, a Comissão Nacional de Educação Jurídica da $\mathrm{OAB}$, reunida em Brasília, indeferiu 18 pedidos de abertura de cursos de direito no país (ORDEM..., 2017). E, ainda, mais um dos motivos de preocupação, é a formação de um grande número de bacharéis sem uma qualificação mínima, se forem analisados os altos índices de reprovação no Exame da Ordem (MARTINES, 2017).

Já, em maio de 2018, por meio da portaria $\mathrm{n}^{\circ}$ 329, o MEC autorizou mais de 5.000 vagas para o curso de direito, dentre as faculdades do Brasil. (BRASIL, 2018). A formação do profissional do Direito pelas faculdades deve levar em conta as Diretrizes Curriculares do Curso de Direito, elaborada pelo MEC, em que se afirma que o curso de direito deve assegurar uma graduação sólida, capaz de assegurar um bom desempenho da Ciência Jurídica (BRASIL, 2004 p. 2-3).

As deficiências, no ensino atual, aliadas ao descomprometimento de alguns discentes e docentes podem levar a um despreparo dentro do mercado de trabalho. $\mathrm{O}$ ensino jurídico encontra-se em uma crise didático-pedagógica, pois a maioria dos professores leciona com base na transmissão dos conteúdos (método catequético), que tem como consequência um aluno que não desenvolve a consciência crítica necessária para refletir sobre os temas discutidos. Quanto às universidades que não se arriscam e tendem a perseverarem suas práticas, querendo honrar as suas tradições, acabam por colocar em risco o futuro da própria instituição (DIAS, 2014, p. 63).

A grande luta é formar um profissional com o domínio do Direito e com competência para lidar com as dificuldades na sociedade contemporânea; por isso, torna-se necessário repensar a metodologia jurídica do próprio direito. O campus deve estar preparado para o surgimento de uma nova pedagogia, o que não significa, necessariamente, o descarte do ensino no método expositivo, mas só ele, no desenvolvimento intelectual atual, não é suficiente. 


\section{DO MÉTODO TRADICIONAL À INOVAÇÃO DO ENSINO HÍBRIDO}

Metodologias de ensino são "práticas pedagógicas operacionalizadas por meio de conjuntos de atividades escolares propostas pelos professores, com vistas a alcançar a aprendizagem de determinados conhecimentos, valores e comportamentos" (TRAVERSINI; BUAES, 2009, p. 145). Existem diferentes métodos de ensino que os professores podem utilizar para repassar o conteúdo da disciplina e a sua bagagem de conhecimento sobre o assunto para os alunos.

No modelo tradicional, o sujeito ativo, no processo de aprendizagem, é o professor o aluno é o sujeito passivo. O professor seria o responsável pelo ensino, e ele apresenta o conteúdo por meio de aulas expositivas (FREITAS, 2012, p. 412-413). Sendo a mais comum das metodologias, a expositiva, em que as atenções centram-se no professor, que transmite as informações e seu conhecimento aos alunos, os quais, por sua vez, são espectadores, pois recebem o conteúdo exposto pelo professor (RODRIGUES, 2010, p. 40).

Com a globalização e as inovações tecnológicas, a sala de aula e o processo de aprendizado devem passar por transformações, de forma a acompanhar essas mudanças. Muitas políticas públicas brasileiras foram debatidas e, de forma inovadora no ensino, em 1996, na reforma da Lei de Diretrizes Básicas da Educação Nacional, é implementada a educação a distância (EAD), em todos os níveis (ALVES, 2007), das escolas às universidades. Esses cursos a distância possuem tecnologia de base que oferecem diferenciais no ensino, por exemplo, acrescentam recursos, como videoconferências, o que faz com que os ambientes virtuais e reais se aproximem. Eles, também, incluem seminários online e fóruns de debate, o que, dificilmente, é oferecido por cursos presenciais tradicionais (CHRISTENSEN; EYRING, 2014, p. 25).

Isso é consequência da busca por novos modelos de aprendizado, pelos educadores, que atendam às necessidades das novas gerações. Na verdade, as universidades tradicionais precisam investir em uma transformação para que possam evoluir no processo de ensino. A proposta do ensino híbrido, de certa forma, seria a união desses dois modelos, a sala de aula tradicional com as vantagens da educação online, fazendo da tecnologia uma aliada ao ensino presencial.

Mais do que incorporar novas tecnologias, o ensino híbrido integra diferentes metodologias de ensino, com a finalidade de aprimorá-lo e torná-lo mais eficiente. Ao tratar do ensino híbrido, a priori, existe toda uma questão conceitual envolvida, de forma que se faz necessária uma breve explanação axiológica a seu respeito. A palavra 'híbrido', de prumo, remete-nos a algo misturado, mesclado, ou seja, a integração de mais de uma coisa.

Ensino híbrido é "qualquer programa educacional formal no qual um estudante aprende, pelo menos em parte, por meio do ensino on-line, com algum elemento de controle dos estudantes sobre o tempo, o lugar, o caminho e/ou ritmo" (HORN; STAKER, 
2015, p. 34). Por meio do ensino híbrido, busca-se um ensino homogêneo, levando-se em consideração a diversidade presente em uma sala de aula, tanto no que diz respeito a alunos, quanto aos professores. Uma das vantagens do uso de estratégias, nesse modelo de ensino, está na melhoria do engajamento dos alunos, por meio de um ensino personalizado, estimulando-os a pensar criticamente, e a trabalhar em grupo, desenvolvendo habilidades sociais e emocionais para além da cognitiva.

Essa metodologia de ensino tem uma subdivisão, em que a primeira é sustentada, em que o tradicional se une a uma nova prática (neste modelo está a Rotação por estações, os Laboratórios Rotacionais e a "sala de aula invertida"). Em um segundo plano, há um modelo disruptivo em que se incluem os modelos Flex e A La Carte, Virtual Enriquecido e Rotação Individual (HORN; STAKER, 2015, p. 168).

Por exemplo, entre os modelos disruptivos, no modelo Flex, o aluno tem uma lista de atividades a ser cumprida, de forma personalizada, online, e com o acompanhamento do professor. No modelo $A$ La Carte, o aluno organiza o seu ritmo de estudo de acordo com sua vida, também personalizado e acompanhado pelo professor que irá direcionar o ritmo adequado (SEBRAE, 2017, p.1).

Por ser algo novo, é natural que docente e o discente levem um tempo de adaptação até que a metodologia de ensino híbrido se consolide como essencial ao ensino. A tecnologia serviria como motores para uma mudança em longo prazo. No que diz respeito a essa adaptação, a tecnologia proveniente do mundo globalizado, Lilian Bacich, Adolfo Tanzi Neto e Fernando de Mello Trevisani (2015, p. 46) esclarecem que:

\begin{abstract}
É possível, portanto, encontrar diferentes definições para ensino híbrido na literatura. Todas elas apresentam, de forma geral, a convergência de dois modelos de aprendizagem: o modelo presencial, em que o processo ocorre em sala de aula, como vem sendo realizado há tempos, e o modelo on-line, que utiliza as tecnologias digitais para promover o ensino. Podemos considerar que esses dois ambientes de aprendizagem, a sala de aula tradicional e o espaço virtual, tornam-se gradativamente complementares. Isso ocorre porque, além do uso de variadas tecnologias digitais, o indivíduo interage com o grupo, intensificando a troca de experiências que ocorrem em um ambiente físico, a escola. O papel desempenhado pelo professor e pelos alunos sofre alterações em relação à proposta de ensino considerado tradicional, e as configurações das aulas favorecem momentos de interação, colaboração e envolvimento com as tecnologias digitais. $O$ ensino híbrido configura-se como uma combinação metodológica que impacta na ação no professor em situações de ensino e na ação dos estudantes em situações de aprendizagem.
\end{abstract}

Da mesma forma que houve mudança na didática de ensino, por conta da era do capitalismo, logo após a Revolução Industrial, o campo educacional visava à preparação do homem como mão de obra qualificada (PILETTI; PILETTI, 2012, p. 14). Assim, do mesmo modo, pode-se repensar na forma de ensino pela globalização na era digital.

Nesse sentido, alguns autores já têm afirmado que "o ensino híbrido está emergindo como uma inovação sustentada em relação à sala de aula tradicional" 
(CHRISTENSEN; HORN; STAKER, 2013, p. 3). É fato que a maioria dos estudantes possuem algum tipo de acesso à tecnologia, por celular, tablet ou notebook e são ferramentas digitais que podem ser usadas em casa e em sala de aula, e poderiam ser incluídas na dinâmica de ensino.

Muitas faculdades já adotam algum tipo de ferramenta online, o que nem sempre acontece é a inclusão em sala de aula. Na proposta de ensino híbrido, o aluno teria acesso à ferramenta, também em sala de aula. Como um modelo disruptivo, em relação ao modelo de sala de aula tradicional, destacam-se, como inovações, os modelos de rotação por estações, laboratório rotacional e "sala de aula invertida", os quais podem ser incorporados tanto em salas de aula tradicional quanto no ensino online.

Como o método ainda é algo novo, torna-se interessante que se possa ser substituído aos poucos e nas matérias que for conveniente. Contudo, não se deve ignorar essa ferramenta ou mesmo fazer dela somente um instrumento acessório. Uma vertente acerca do assunto Christensen e Eyring (2014, p. 26) relatam que:

\begin{abstract}
Embora as universidades tradicionais continuem a desempenhar uma função essencial e única no sentido de descobrir novos conhecimentos e de preservar o saber, e de promover a educação dos estudantes em comunidades que contam com a presença de acadêmicos, elas também se deparam com inovações disruptivas que clamam por um reexame daquelas. Não obstante, se as universidades tradicionais não conseguirem descobrir um jeito de desempenhar suas valiosas e incomparáveisfunções, estarão condenadas a perder as altas posições que detêm no cenário nacional e mundial.
\end{abstract}

Acerca de tecnologias disruptivas, na qual se faz uma mistura entre o antigo/novo de forma a impactar o ensino tradicional, nasce uma nova forma de ensinos em se afastar do tradicional e, ao mesmo tempo, não gerar impacto muito grande, por conta da mudança de antigos hábitos (CHRISTENSEN; HORN; STAKER, 2013, p. 25). O ensino híbrido se traduz em um aperfeiçoamento do ensino, já que, com o emprego de novas tecnologias, bem como o ensino online, facilita-se o aprendizado, afastando-se daquele modelo único dentro de sala de aula.

A opção disruptiva, no caso, do ensino híbrido, é exatamente essa, integrar o tecnológico e o tradicional, para, ao fim, resultar em uma melhor forma de didática e ensino. Ele pode fazer parte na dinâmica principal da aula e, nesse sentido, todo o tripé (aluno, professor e universidade) tem que funcionar. A Universidade deve prover de espaços estilizados e capacitados para essa forma de ensino e o professor deve ser capacitado por meio de cursos de capacitação. Não diferente, o aluno que tiver dificuldade no uso de tecnologias, deve ser auxiliado de forma especial pelo professor, monitor ou pessoa específica.

Deve ser ressaltado que o propósito do ensino de modo híbrido não é proporcionar o estudo online em casa e simplesmente trocar o ambiente da sala de aula pelo quarto, 
mas proporcionar uma experiência integrada de aprendizagem, de forma que o aluno possa, de alguma forma, controlar ritmo, espaço e tempo e esteja no centro do processo.

Todavia, no que diz respeito à experiência dentro do ensino jurídico, resta o questionamento acerca da efetividade desse modelo e os desafios a serem enfrentados com a sua implantação, já que ainda não há dados sobre a aplicação dessa metodologia no curso. O que é exatamente a proposta do artigo, levar o debate acerca da implantação desse método de ensino no referido curso.

\section{O ENSINO HÍBRIDO NA REALIDADE DA DIDÁTICA APLICADA AO DIREITO: A EXPERIÊNCIA DA "SALA DE AULA INVERTIDA"}

Superadas as primeiras impressões acerca do conceito de ensino híbrido, questiona-se a adequação desse modelo para o ensino jurídico, visto que referido modelo já se encontra sendo aplicado, com êxito, em algumas escolas, principalmente no que diz respeito ao ensino médio (BACICH; TANZI NETO; TREVISANI, 2015, p. 47). No Brasil, a metodologia tem dado certo nos Ginásios Experimentais Cariocas (rede de escolas criada pela Prefeitura do Rio de Janeiro), aplicada nas disciplinas de ciências e matemática, na qual se constata depoimentos positivos, por parte dos professores (SEBRAE, 2017).

O cerne da questão no ensino híbrido, para a sua utilização no ensino jurídico, se traduz-se nas metodologias de ensino ativo, notadamente no que diz respeito ao modelo de "sala de aula invertida" ou flipped classroom, que tem como principal eixo o fato de o aluno ter prévio acesso ao material do curso para que possa discutir o conteúdo com o professor e os demais colegas da sala (BERGMANN; SAMS, 2016, p. 45). Essa metodologia já vem sendo utilizada em várias áreas no ensino superior, nesse sentido (PINTO et al. 2012, p. 23):

\footnotetext{
Aprendizagem ativa significa aprendizado dinâmico, no qual, por meio de atividades baseadas em projetos, colaborativas e centradas em soluções de problemas, os estudantes desempenham um papel vital na criação de novos conhecimentos, que podem ser aplicados a outras áreas acadêmicas e profissionais; ampliando o seu engajamento com a realidade externa da escola. (...). Este processo de aprendizagem ativa é permeado por organização independente, medida pelo professor, que permite a construção de conhecimentos social e historicamente significativos em que, por meio da práxis educativa, o aluno exercita a sua capacidade de reflexão e de ação em relação à realidade em que está inserido.
}

Mesmo que observada a forma tradicional, em que o aluno deve sempre estudar o conteúdo antes da aula, não é isso que normalmente acontece. Há algumas falhas, seja porque o professor não disponibiliza o material antes, seja porque o calendário de aula não esteja previamente apresentado aos alunos, ou, ainda, em qualquer das hipóteses, o professor não tem acesso a nenhum controle sobre o acesso a informação. 
Por isso, a sala de aula se transforma em um espaço interativo, dinâmico e capaz de estimular debates. Oliveira (2016, p. 68) esclarece que, por meio de metodologias ativas, há a inserção do estudante como o agente principal, o responsável pela sua aprendizagem. O aluno passa a ficar comprometido com seu aprendizado, sendo necessário que o aluno estude o conteúdo, em seu tempo, fora da classe para que possa acompanhar as discussões, ficar centrado na realidade em que está inserido e permite que as lacunas na compreensão do conteúdo se tornem mais visíveis.

A referida autora, ao tratar da "sala de aula invertida", explica que se propõe a inversão do modelo de ensino tradicional, à medida que se faz necessário e imperioso que aluno antecipe a leitura, de forma a acompanhar a aula e que as tarefas que eram destinadas à lição de casa possam a ser realizadas também em sala de aula.

A implantação dessas metodologias ativas se deve, ainda, aos novos perfis profissionais dos docentes, não somente no direito, mas em todas as áreas de conhecimento. Tem-se exigido mais do professor, tanto no quesito qualificação, quanto no quesito criatividade. O que incita o raciocínio prévio e eleva o papel do professor, que fica disponível para tirar dúvidas, realizar atividades de compreensão e aprofundar o tema, estimulando o debate.

É possível concluir que, com essa modalidade de metodologia ativa, o aluno se comporta como protagonista da aprendizagem, de modo a tornar a aula menos cansativa e mais proveitosa. A responsabilidade pela aquisição do conhecimento em metodologias ativas de ensino é compartilhada entre aluno e professor, posto que, a exemplo da "sala de aula invertida", o aluno não fica apenas no papel de mero receptor da informação exposta pelo professor, mas tem o dever de compartilhar aquilo que aprendeu por meio das ferramentas concedidas previamente. É exatamente o que Bacich, Tanzi Neto e Trevisani (2015, p. 48) explicam:

Nesse ambiente diferenciado, os alunos são identificados com base em seus conhecimentos ou habilidades específicas em uma área, e o professor organiza a classe em grupos por afinidades para atendê-la melhor. Em um ambiente de aprendizagem personalizado, o aprendizado começa com o aluno. O aprendiz informa como aprende melhor para que organize seus objetivos de forma ativa, junto com o professor. Em um ambiente de aprendizado individualizado, a aprendizagem é passiva. Os professores fornecem instruções individualmente. $\mathrm{O}$ aluno não tem voz em seu projeto de aprendizagem. Em uma sala de aula diferenciada, os estudantes podem ser participantes ativos em sua aprendizagem. Os professores modificam a forma de ensinar por meio de estações ou aula invertida, apresentando o mesmo conteúdo para diferentes tipos de alunos, mas que ainda recebem informações de forma passiva. Quando os estudantes personalizam a sua aprendizagem, eles participam ativamente, dirigindo seu processo e escolhendo uma forma de aprender melhor.

Ocorre que, além da resistência enfrentada em relação à adequação do professor ao modelo de ensino híbrido, também há o enfrentamento da resistência do aluno, que 
se encontra "viciado" naquela modelo tradicional de aula expositiva e entende, de forma errônea, os objetivos almejados com o surgimento do modelo de ensino híbrido.

Nesse contexto, em uma pesquisa realizada pelo laboratório de pesquisa da Universidade de Stanford, fora verificado que o uso de tecnologias e métodos não tradicionais de ensino, aumenta em pelo menos $25 \%$ o desempenho dos alunos (SCHNEIDER; BLIKSTEIN; PEA, 2013, p. 1):

In a controlled study conducted in our lab, we found that, compared to traditional text learning, performance increased significantly with the use of these tangible, interactive tools. We found a 25 percent increase in performance when open-ended exploration came before text study rather than after it. Our results show that the participants who used BrainExplorer better remembered the terminology of the domain, scored higher on conceptual questions and were better able to transfer their understanding of the brain to new situations. ${ }^{1}$

É bem verdade que, atualmente, prender a atenção de um aluno tem se tornado cada vez mais difícil, razão pela qual a educação tem de se reinventar constantemente, tanto no que diz respeito ao ensino fundamental e médio, quanto no que diz respeito ao ensino superior.

A efetividade da participação ativa do aluno é facilmente observada em programas de pós-graduação stricto sensu, notadamente no que diz respeito à área do direito, na qual suas aulas são compostas, basicamente, pelo debate e diálogo entre os alunos e o professor, os quais, por sua vez, já chegam à aula com o conteúdo visto na graduação ou no trabalho. Ou seja, entende-se que, dessa forma, há o compartilhamento da aprendizagem por parte da turma.

É indubitável a viabilidade do ensino híbrido no ensino do direito, notadamente no que concerne a metodologias ativas, as quais já são frequentemente utilizadas, e vem ganhando cada vez mais espaço em algumas universidades do país.

\section{CONCLUSÃO}

O esforço pela recomposição dos níveis de qualidade do ensino superior de direito deve ser acompanhado pelo desenvolvimento científico e tecnológico que se projeta na sociedade e se concretiza no engajamento professor, aluno e Instituição de Ensino Superior (IES). O melhor projeto pedagógico não será consolidado se não houver compromisso desse tripé.

\footnotetext{
${ }^{1}$ Em tradução livre: "Em um estudo controlado conduzido em nosso laboratório, descobrimos que, em comparação com a aprendizagem de texto tradicional, o desempenho aumentou significativamente com 0 uso dessas ferramentas tangíveis e interativas. Nós encontramos um aumento de $25 \%$ (vinte e cinco por cento) no desempenho quando a exploração aberta veio antes do estudo do texto do que depois dele. Nossos resultados mostram que os participantes que usaram BrainExplorer se lembraram melhor da terminologia do domínio, obtiveram pontuações mais altas em questões conceituais e foram mais capazes de transferir sua compreensão do cérebro para novas situações. ".
} 
O desafio de ruptura do modelo tradicional de ensino, no qual é reproduzido pelo ensino, essencialmente, mecanicista de repasse pelo professor de modo organizado e sistemático de conteúdos e de memorização pelo aluno, deve ser revisto.

É importante discutir maneiras inovadoras para melhorar a forma de interação na relação aluno-professor, com a implementação do ensino participativo na construção de conhecimentos. Os estudantes compreendem que são sujeitos de sua aprendizagem e que, a cada aula, podem modificar seu modo de pensar e adquirir novos saberes.

O processo de adequação de todos os atores envolvidos (professor, faculdade e aluno), na nova dinâmica de ensino não é construído de uma hora para a outra, é necessário um tempo de acomodação.

Conscientes das inúmeras possibilidades de engajamento, reestruturação e inovação, apresentam-se algumas propostas para a reflexão sobre o tema, sempre na busca de uma melhoria na qualidade da educação. Dessa forma, entende-se que o ensino híbrido, nas IES, parte da utilização de tecnologia para auxiliar a implementação do ensino participativo, colaborativo, notadamente, porque sintonizado com tempos de redes sociais e internet, pode proporcionar aos discentes, maior autonomia, tanto no quesito tempo quanto no quesito aprendizado. Além de ser uma ferramenta capaz atrair a atenção do aluno porque combina atividades presenciais e atividades realizadas por meio das tecnologias digitais.

No exame da metodologia da "sala de aula invertida", os estudantes acessam os conteúdos que são disponibilizados online de forma independente, fora do horário de aula, pois nela eles se dedicam a tirar dúvidas e colocar em prática o que aprenderam na plataforma digital, com a realização de exercícios e atividades em grupo, por exemplo. Essa modalidade de ensino possibilita a personalização do ensino, atendendo ao ritmo de aprendizagem de cada aluno. A combinação entre o ensino presencial com o virtual dentro e fora da escola proporciona aos estudantes acesso a um aprendizado inovador. O bom uso dos novos recursos tecnológicos pode favorecer o aprendizado.

A implantação do ensino híbrido, nas IES de todo país, pode vir a enfrentar diversos desafios, pois, para a sua utilização efetiva, faz-se necessária uma série de elementos, desde a reestruturação do ensino superior, que deve proporcionar um local hábil para a realização dessa forma de ensino, tão quanto às capacitações aos docentes, no campo tecnológico e nos diálogos entre as metodologias ativas propostas pelo referido modelo. Também é possível que os próprios estudantes tenham que passar por uma adaptação até se sentirem confortáveis com a "sala de aula invertida", dentro da aprendizagem híbrida.

A tecnologia exerce importante influência sobre a reflexão das práticas docentes. É preciso, sobretudo, superar aquele modelo de aula eminentemente expositiva, posto que o ensino jurídico não deva ser limitado a mera transferência mecânica de 
informações entre o aluno e o professor, isso se traduz em uma quebra de paradigma necessária para uma melhor efetividade do ensino jurídico no país.

Desta forma, entende-se que a combinação de aprendizagens individuais e em grupo, com o uso da tecnologia, entre alunos e mediada por professores mais experientes, traduz-se na melhor e mais efetiva forma de aprendizagem, nos tempos contemporâneos.

\section{REFERÊNCIAS}

ALVES, João Roberto Moreira. A História da Educação a Distância no Brasil. Carta Mensal Educacional, v. 82, n. 16, jun. 2007. Disponível em: <http://www.ipae.com.br/pub/pt/cme/cme_82/index.htm>. Acesso em: 12 jan. 2018.

BACICH, Lilian; TANZI NETO, Adolfo; TREVISANI, Fernando de Mello (Org.). Ensino híbrido: personalização e tecnologia da educação. Porto Alegre: Penso, 2015.

BRASIL. Portaria $n^{\circ}$ 329, de 11 de maio de 2018. Diário Oficial da União. Brasília, DF, 14 maio 2018.

Resolução $n^{\circ}$ 9, de 29 de setembro de 2004. Institui as Diretrizes Curriculares Nacionais do Curso de Graduação em Direito e dá outras providências.Conselho Nacional de Educação Câmara de Educação Superior. Brasília, DF, 1 out. 2004. Disponível em: <http://portal.mec.gov.br/cne/arquivos/pdf/rces09_04.pdf>. Acesso em: 20 fev. 2018.

BENTO, Flávio; SANCHES, Samyra Haydêe dal Farra Naspolini. A história do ensino do direito no Brasil e os avanços da portaria 1886 de 1994. In: CONGRESSO NACIONAL DO CONPEDI, 18, 2009, São Paulo. Anais..., Florianópolis: Fundação Boiteux, 2009, p. 6186 - 6211. Disponível em: <https://s3.amazonaws.com/conpedi2/anteriores/XVIII+Congresso+Nacional+-+FMUSão+Paulo+(04,+05,+06+e+07+de+novembro+de+2009).pdf>. Acesso em: 07 jan. 2018.

BERGMANN, Jonathan; SAMS, Aaron. Sala de aula invertida: uma metodologia ativa de aprendizagem. 1. ed. Rio de Janeiro: LTC, 2016.

CHRISTENSEN, Clayton M.; EYRING, Henry J. A Universidade Inovadora: Mudando o DNA do Ensino Superior de Fora para Dentro. Porto Alegre: Bookman, 2014.

CHRISTENSEN, Clayton M; HORN, Michael B; STAKER, Heather. Ensino Híbrido: uma inovação disruptiva? Uma introdução à teoria dos híbridos. Clayton Christensen Institute, 2013.

DIAS, Renato Duro. Relações de Poder e Controle no Currículo do Curso de Direito da FURG. 2014. 349 f. Tese (Doutorado) - Universidade Federal de Pelotas, Pelotas, 2014. Disponível em: <http://guaiaca.ufpel.edu.br/bitstream/prefix/3348/1/DIAS, Renato Duro.pdf>. Acesso em: 09 jan. 2018.

DURKHEIM, Emile. A evolução pedagógica. Porto Alegre: Artes Médicas, 1995. 
FREIRE, Paulo. A pedagogia do oprimido. 17. ed. Rio de Janeiro: Paz e Terra, 1987.

FREITAS, Raquel Aparecida Marra da Madeira. Ensino por problemas: uma abordagem para o desenvolvimento do aluno. Educação e Pesquisa, v. 38, n. 2, p. 403-418, 2012.

FOREQUE, Flávia. MEC decide limitar expansão de cursos de direito em todo o país.

Folha de S. Paulo, 2013. Disponível em:

$<$ http://www1.folha.uol.com.br/educacao/2013/02/1234866-mec-decide-limitar-

expansao-de-cursos-de-direito-em-todo-pais.shtml>. Acesso em: 05 jan. 2018.

HORN, Michel B.; STAKER, Hearther. Blended: usando a inovação disruptiva para aprimorar a educação. Porto Alegre: Penso. 2015.

INSTITUTO NACIONAL DE ESTUDOS E PESQUISAS EDUCACIONAIS ANÍSIO TEIXEIRA (INEP). Censo da Educação Superior: principais resultados. Brasília: MEC, 2016. Disponível em:

<https://abmes.org.br/arquivos/documentos/censo_superior_tabelas.pdf>. Acesso em: 10 jan. 2018.

MARTINES, Fernando. Primeira fase do Exame de Ordem tem recorde de candidatos reprovados. Consultor Jurídico. 2017. Disponível em:

$<$ https://www.conjur.com.br/2017-set-01/primeira-fase-exame-ordem-recordereprovacoes>. Acesso em: 08 jan. 2018.

MOSSINI, Daniela Emmerich de Souza. Ensino jurídico: história, currículo e interdisciplinaridade. 2010. 249 f. Tese (Doutorado em Educação) - Pontifícia Universidade Católica de São Paulo, São Paulo, 2010. Disponível em:

$<$ https://tede2.pucsp.br/bitstream/handle/9534/1/Daniela Emmerich de Souza Mossini.pdf>. Acesso em: 29 jun. 2018.

OLIVEIRA, Eliana Maria P. de. Docência em direito e a "sala de aula invertida" como opção metodológica ativa. Evidência, v. 12, n. 12, p. 59-77, 2016.

ORDEM DOS ADVOGADOS DO BRASIL - OAB. Comissão de Educação Jurídica nega pedido de abertura de 18 cursos de direito. Elabora por Conselho Federal da Ordem dos Advogados do Brasil, 2017. Disponível em:

<http://www.oab.org.br/noticia/56004/comissao-de-educacao-juridica-nega-pedido-deabertura-de-18-cursos-de-direito?argumentoPesquisa=faculdades de direito $>$. Acesso em: 8 jan. 2018.

PILETTI, Claudino; PILETTI, Nelson. História da Educação: de Confúcio a Paulo Freire. São Paulo: Contexto, 2012.

RODRIGUES, H. W. Popper e o processo de ensino-aprendizagem pela resolução de problemas. Revista Direito GV, v. 6, n. 1, p. 39-57, 2010.

SCHNEIDER, Bertrand; BLIKSTEIN, Paulo; PEA, Roy. The Flipped, Flipped Classroom. The Stanford Daily. Stanford, 7 ago. 2013. Disponível em: $<$ https://www.stanforddaily.com/2013/08/05/the-flipped-flipped-classroom/>. Acesso em: 11 nov. 2016. 
SEBRAE. Observatório cer ensino híbrido: o caminho para uma nova educação. 2017. Disponível em: <http://cer.sebrae.com.br/ensino-hibrido/>. Acesso em: 27 fev. 2018.

SILVA, Artenira da Silva e; SERRA, Maiane Cibele de Mesquita. Juristas ou técnicos legalistas? Reflexões sobre o ensino jurídico no brasil. Revista Quaestio luris, v. 10, n. 4, p. 2616-2636, 2017. Disponível em: <http://www.epublicacoes.uerj.br/index.php/quaestioiuris/article/view/28197/21901>. Acesso em: 10 jan. 2018.

PINTO, Antonio et al. O laboratório de metodologias inovadoras e sua pesquisa sobre o uso de metodologias ativas pelos cursos de licenciatura do UNISAL, Lorena: estendendo o conhecimento para além da sala de aula in Revista de Ciências da Educação, v. 2, n. 9, p. 67-79, 2013.

SIQUEIRA, Márcia Dalledone. Faculdade de Direito: 1912-2000. Curitiba: Universidade Federal do Paraná, 2000.

TRAVERSINI, C. S.; BUAES, C. S. Como discursos dominantes nos espaços da educação atravessam práticas docentes? Revista Portuguesa de Educação, v. 22, n. 2, p. 141-158, 2009. 